\title{
Novel scientific approaches and future research directions in understanding ITP
}

Sarah M. Hicks, Lucy A. Coupland, Anila Jahangiri, Philip Y. Choi \& Elizabeth E. Gardiner

To cite this article: Sarah M. Hicks, Lucy A. Coupland, Anila Jahangiri, Philip Y. Choi \& Elizabeth E. Gardiner (2020) Novel scientific approaches and future research directions in understanding ITP, Platelets, 31:3, 315-321, DOI: 10.1080/09537104.2020.1727871

To link to this article: https://doi.org/10.1080/09537104.2020.1727871

册Published online: 13 Feb 2020.

Submit your article to this journal

山ll Article views: 126

Q View related articles $₫$

View Crossmark data 


\title{
Novel scientific approaches and future research directions in understanding ITP
}

\author{
Sarah M. Hicks (1) ${ }^{1}$, Lucy A. Coupland $\mathbb{1}^{1,2}$, Anila Jahangiri ${ }^{1}$, Philip Y. Choi $\mathbb{1}^{1,2,3}$, \& Elizabeth E. Gardiner (1) ${ }^{1,2}$ \\ ${ }^{7}$ ACRF Department of Cancer Biology and Therapeutics, The John Curtin School of Medical Research, The Australian National University, Canberra, \\ Australia, ${ }^{2}$ The National Platelet Research and Referral Centre (NPRC), Canberra, Australia, and ${ }^{3}$ Haematology Department, The Canberra Hospital, \\ Canberra, Australia
}

\section{Abstract}

Diagnosis of immune thrombocytopenia (ITP) and prediction of response to therapy remain significant and constant challenges in hematology. In patients who present with ITP, the platelet count is frequently used as a surrogate marker for disease severity, and so often determines the need for therapy. Although there is a clear link between thrombocytopenia and hemostasis, a direct correlation between the extent of thrombocytopenia and bleeding symptoms, especially at lower platelet counts is lacking. Thus, bleeding in ITP is heterogeneous, unpredictable, and nearly always based on a multitude of risk factors, beyond the platelet count. The development of an evidence-based, validated risk stratification model for ITP treatment is a major goal in the ITP community and this review discusses new laboratory approaches to evaluate the various pathobiologies of ITP that may inform such a model.
\end{abstract}

\section{Keywords}

Autoantibody, ITP, platelet, receptor, thrombocytopenia

\author{
History \\ Received 4 February 2020 \\ Revised 5 February 2020 \\ Accepted 6 February 2020 \\ Published online 16 February 2020
}

\section{Introduction}

Immune thrombocytopenia (ITP) is an acquired autoimmune disorder characterized by a moderate to a severe reduction in platelet count in peripheral blood and where there is no other cause or disorder associated with thrombocytopenia. In healthy individuals, the platelet count ranges from 150 to $400 \times 10^{9} / \mathrm{L}$, however in ITP, the platelet count falls below $100 \times 10^{9} / \mathrm{L}$ [1]. In adults, the incidence of ITP is approximately two to four per 100,000 [2]; however, these numbers may be inaccurate. In fact, ITP is likely to be under or even misdiagnosed [3] as clinical diagnosis is by exclusion, both patient presentation and disease etiology are diverse and nonuniform, and in the absence of meaningful standardized tests, the simple platelet count remains the primary tool for diagnosis and evaluation of response to therapy. Distinguishing ITP from other forms of acquired thrombocytopenia such as drug-induced thrombocytopenia is crucial for diagnosis and for implementation of the appropriate medical treatment (Figure 1) [4]. New diagnostic approaches that can assess platelet quality and functional changes are desperately needed as novel clinical therapies become available. Further, application of these new research-based approaches to evaluate platelet and immune cell levels and function in samples from people with ITP in a measured and strategic fashion is likely to simultaneously improve our understanding of the etiology and pathology of ITP.

Contribution to the Special Focus Issue on Immune Thrombocytopenia Correspondence: Elizabeth Gardiner ACRF Department Cancer Biology and Therapeutics, John Curtin School of Medical Research, Australian National University, 131, Garran Rd, Acton, ACT 2601, Australia. E-mail: elizabeth.gardiner@anu.edu.au

\section{Mechanisms of Disease in ITP}

ITP is an acquired heterogeneous autoimmune disorder characterized by phagocytosis of autoantibody-coated platelets by splenic macrophages and complement- or $\mathrm{T}$ cell-mediated platelet destruction (Figure 2) [5]. The targets of autoantibodies, primarily of the immunoglobulin (Ig) G class, are specific glycoprotein (GP) receptors found on platelets and the parental bone marrow megakaryocyte. In ITP the major antigenic receptor targets are GPIb-IX-V (primarily the GPIb $\alpha$ subunit but also GPV) and $\alpha \operatorname{IIb} \beta 3$ [6-8], although antibodies against GPVI and $\alpha 2 \beta 1$ have also been reported $[9,10]$. Binding of these autoantibodies to platelets triggers destructive processes often mediated by $\mathrm{Fc}$ receptor (FcR) on macrophages as well as inhibition of platelet function and platelet production by megakaryocytes. Levels of thrombopoietin (TPO), mostly a liver-derived hormone that drives megakaryocyte maturity and platelet production, are generally not different in ITP patients from levels measured in healthy donors $[11,12]$. Although the measurement of TPO levels is unable to confirm a diagnosis of ITP, as this entity remains a diagnosis of exclusion, elevated TPO levels may help suggest an alternative cause for thrombocytopenia [12]. The observation that TPO levels are inappropriately modest in ITP suggests that this underexpression contributes to the pathogenesis of the disease. The onset of ITP has no clear underlying cause but seems to develop through loss or perturbation of B- and T-cell immune tolerance via diverse mechanisms. An abnormal T cell response, driven by splenic $\mathrm{T}$ follicular helper cells, stimulates the proliferation and differentiation of autoreactive $\mathrm{B}$ cells. Altered $\mathrm{T}$ helper cell ratios and changes to attendant cytokines such as interleukin (IL)-17 have also been reported to contribute to ITP pathology [13]. Cytotoxic $\mathrm{T}$ cells have been demonstrated targeting platelets in the periphery, as well as affecting megakaryocyte proplatelet formation in the bone marrow niche $[14,15]$. 


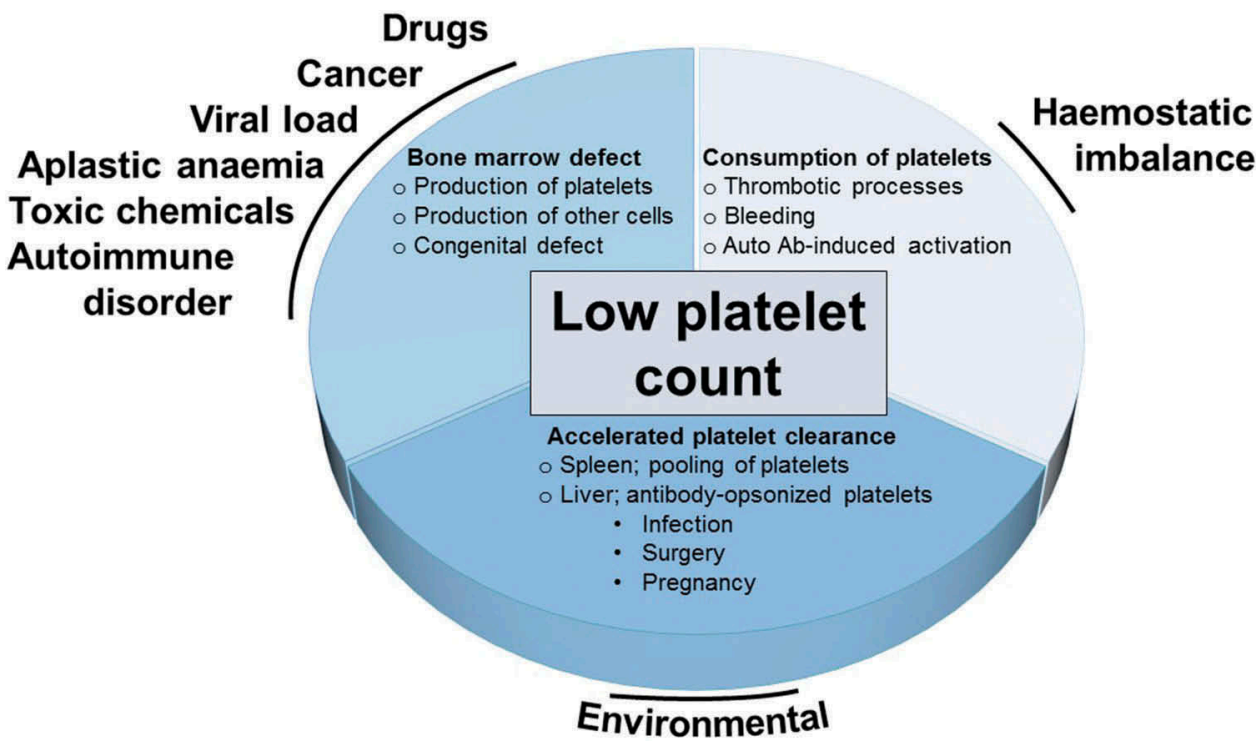

Figure 1. Factors that lead to a low platelet count.A low platelet count can result from one or more main elements; reduced production of platelets by megakaryocytes in the bone marrow, increased consumption of platelets in hemostatic processes and accelerated clearance of platelets. Exposure to toxic chemicals and chemotherapy, autoimmune disorders and other pathologies can disturb the bone marrow niche and platelet production by megakaryocytes. Certain drugs have been associated with the development of drug-dependent anti-platelet antibodies. Reduction in platelet count can also arise from extensive consumption of platelets in hemostatic processes. Furthermore, the production of anti-platelet autoantibodies can result in inappropriate platelet activation and opsonization leading to clearance via the spleen where antibody-opsonized platelets are removed by splenic macrophages or via the liver where Kupffer cells remove activated/desialylated platelets. External triggering factors such as infection, pregnancy and surgery can also trigger thrombocytopenia however the mechanisms have not been elucidated.

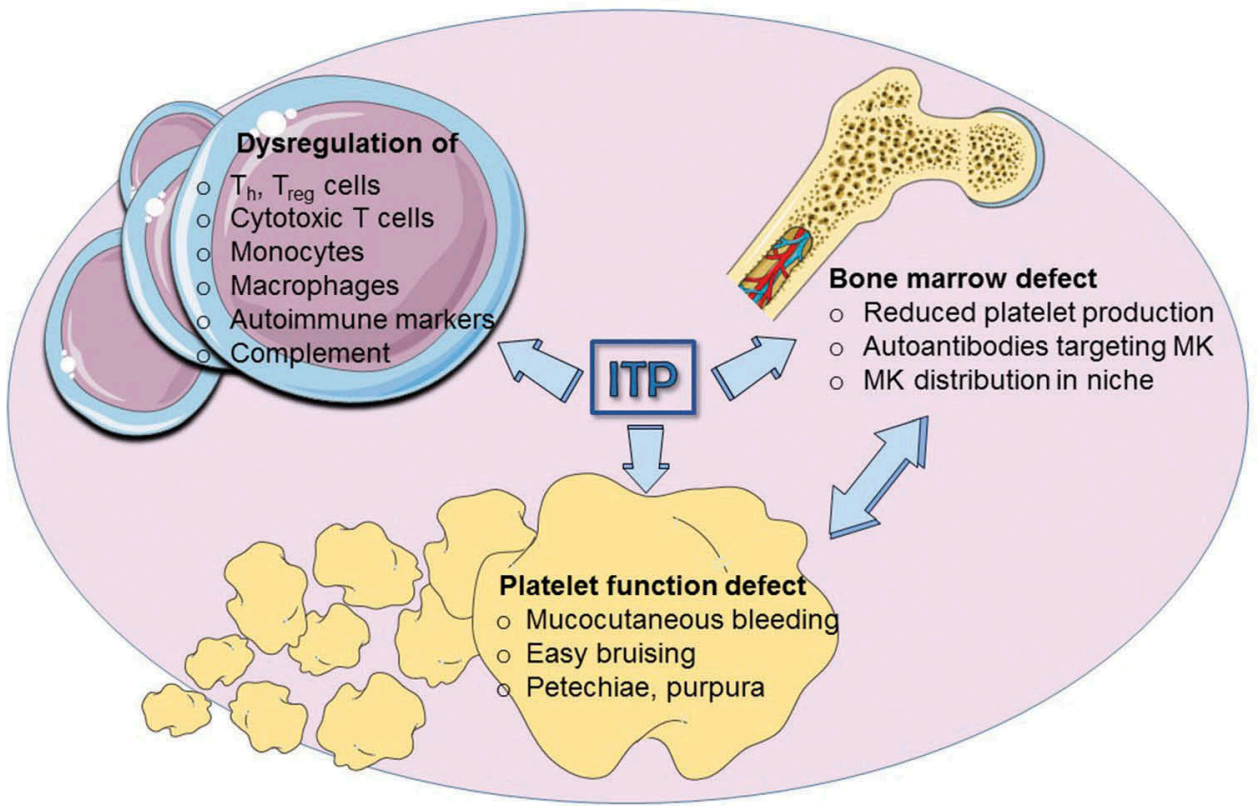

Figure 2. Pathophysiology of immune thrombocytopenia.The pathophysiology of ITP stems from dysregulation of the immune system and disturbed bone marrow and platelet function. Control of an appropriate $\mathrm{T}$ cell response is lost, with increased T helper 1 cells and decreased $\mathrm{T}$ regulatory cells leading to increased macrophage-mediated phagocytosis and presentation of platelet antigens to T and B cells. Autoantibodies produced by B cells opsonize platelets leading to complement-mediated and phagocytic clearance. Loss of platelet numbers and function through autoantibody binding to both platelets and bone marrow megakaryocytes can result in mild to severe bleeding symptoms. Immune cell dysregulation can also directly affect the bone marrow niche.

\section{Current Means to Diagnose ITP}

There is no diagnostic test or reliable panel of biomarkers to direct treatment, and few comparative studies to help management decisions around ITP, and this syndrome remains diagnosed by the exclusion of other known causes [2, 16]. Response to ITP-specific therapy, for example, intravenous immunoglobulin (IVIg) and intravenous anti-D, is supportive of the diagnosis, but a platelet response does not confirm a diagnosis either. As people with ITP often present with fatigue and unexplained mild bleeding, the platelet count in association with blood and bone marrow smears remain the major clinical tools to evaluate an isolated thrombocytopenia. Secondary causes for ITP need to be excluded with screening for autoimmune diseases, serology for hepatitis $\mathrm{C}$ virus, human immunodeficiency virus and in some regions Helicobacter pylori testing [16, 17]. 
A whole blood smear in combination with immunocytochemical staining using monoclonal antibodies (mAbs) and qualitative analysis by light microscopy can reveal changes in platelet morphology as well as reduction of platelet receptor levels and help rule-out disorders of macrothrombocytopenia [18]. Measurement of platelet diameter may be helpful to distinguish ITP from other inherited forms of thrombocytopenia [19].

Notwithstanding procedural nuances that can impact on the counting of platelets, including the choice of anticoagulant in which to collect the blood, and the mode of automated counter (optical or impedance) used to enumerate platelets, the platelet count remains just a broad guide of disease status. It does not predict treatment responses or duration of response or provide a means to stratify patients for bleeding risk. Some measurements are only available in reference centers including quantification of reticulated (new) platelets, serum thrombopoietin (TPO) and platelet sequestration studies which remain of disputed benefit from conflicting data [20-23].

\section{Avenues to Investigate ITP Pathogenesis}

As our understanding of the pathogenesis of ITP is strengthening, research-based approaches that focus on measuring the underlying causes of this syndrome may have utility to evaluate ITP pathology in patients and assist in the diagnosis of ITP (Figure 3 ). This will be particularly valuable if new approaches can enable stratification of patients into therapeutic groups, as well as identification of patients at risk of relapse and of bleeding.

\section{Characterizing Antiplatelet Autoantibodies}

Autoantibodies against platelet antigens are considered a diagnostic hallmark of ITP; however, reliable detection of pathological antibodies is challenging due to variable levels of free versus platelet-bound antibodies, and an absence of detectable anti-platelet autoantibodies in up to $40 \%$ of patients [24]. In some patients, antibodies recognize antigens derived from a single glycoprotein; whereas in others, antibodies recognize multiple glycoproteins [25]. Although the prognostic value of platelet antibodies to date is limited, it might be helpful to characterize the target of an antiplatelet autoantibody as specific types of antibody may predict responses to steroids or IVIg [26, 27] and may predict chronic disease and bleeding [28]. More recently, antibodymediated desialylation of platelets in ITP has been reported to occur in patients with anti-platelet antibodies, raising the possibility that these patients could be treated with a neuraminidase inhibitor such as oseltamivir [29-31].

Direct and indirect forms of the Monoclonal Antibody-specific Immobilization of Platelet Antigen (MAIPA) assay using patient or donor platelets are designed to detect and characterize the autoantibody target [32]. Indirect MAIPA positivity at disease onset was observed to be associated with more severe hemorrhage and predicted a chronic course in adult ITP patients [28]. In this assay, platelets from donors or patients are isolated and washed, then mixed separately with mouse mAbs directed against various human platelet receptors, primarily GPIb-IX-V, $\alpha \operatorname{IIb} \beta 3$ or $\alpha 2 \beta 1$ which are the major platelet antigens in ITP. Platelets are then washed and solubilized by detergent-containing buffer and plated onto 96-well plates coated with anti-mouse IgG. The wells are washed and incubated with a peroxidase- or phosphataseconjugated anti-human IgG antibody followed by substrate. Detection of a signal signifies the presence of autoantibodies in complex with the mAb-bound platelet receptor captured by the anti-mouse IgG. This assay requires specialist laboratory training and does not report on autoantibody binding affinity or avidity. Also, a lack of signal indicates only that antiplatelet autoantibodies

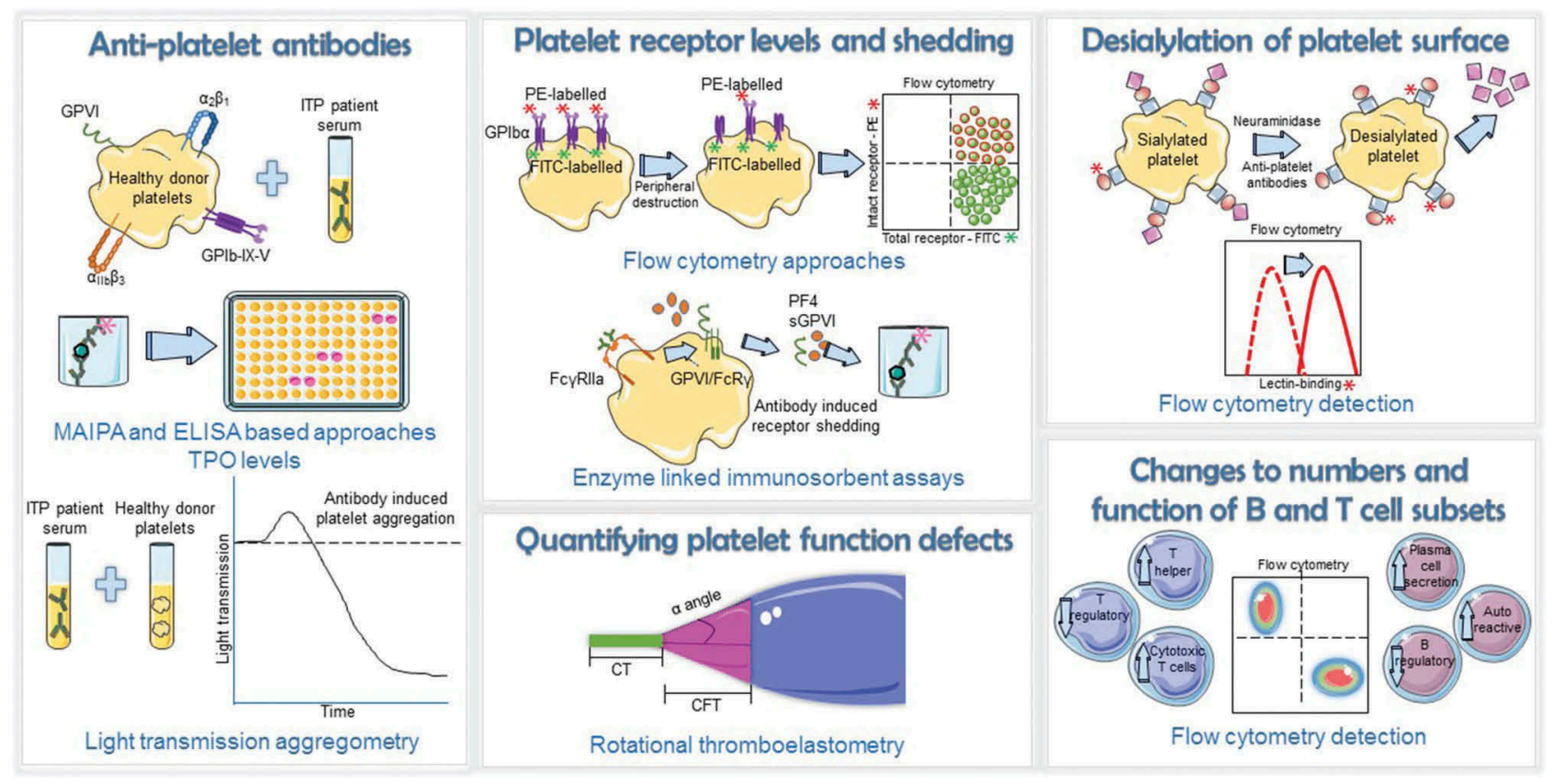

Figure 3. Some existing and new laboratory approaches to aid diagnosis of ITP.Some existing and new research-based methods that can be applied to evaluate ITP both at initial presentation and in a patient receiving treatment focus on evaluating antibody-induced changes to platelet function, detection and characterization of anti-platelet autoantibodies and enumerating immune cell subsets and specific functions (e.g. cytokine production). A new assay evaluates the levels of intact and total GPIb $\alpha$ present on circulating platelets, to gauge peripheral destruction of platelets. PF4 and sGPVI are released from antibody-bound platelets and can be batch analyzed by ELISA. Desialylation of the platelet surface (predominantly GPIb $\alpha$ ) can be evaluated by flow cytometry using fluorescence-labeled lectins. Assessment of T and B cell subsets by flow cytometry and functional assays can also report on the extent of immune dysregulation. Ongoing and future work will evaluate the utility of each of these assays to inform clinical decisions, predict bleeding and assess responses to therapies. 
that target the receptors specified are not detected, neglecting alternate epitopic specificity. Further, as mAbs against GPVI are generally not included in a standard MAIPA, autoantibodies that bind GPVI will not be detected. A version of the MAIPA using beads coated with mAbs against GPIb $\alpha$ or $\alpha$ IIb integrin that was mixed with patient washed platelet lysates followed by a radiolabeled anti-human IgG antibody has been used with reasonable specificity but only modest sensitivity [24].

\section{Platelet-associated Immunoglobulins}

Approaches that use flow cytometry to evaluate the platelet surface for the presence of antibodies (platelet-associated IgG; PaIgG) also have been described. Samples of patient whole blood are mixed with fluorescently tagged anti-human IgG antibodies and evaluated for fluorescence activity. This approach has the advantage of being able to directly interrogate samples of anticoagulated whole blood from patients, rather than use surrogate donor platelets, as flow cytometry is sufficiently sensitive to be able to monitor the platelet surface in thrombocytopenic samples even when the platelet count is extremely low $\left(<5 \times 10^{9} / \mathrm{L}\right)$. The disadvantage of this approach is the lack of specificity [33] as PaIgG may be elevated in both immune and nonimmune thrombocytopenia [34]. Interestingly, the population of PaIgG-positive platelets detected in peripheral blood is likely to be the 'surviving' platelets that have not been cleared by the reticuloendothelial system and may themselves be worthy of investigation.

\section{Evaluating Age of Circulating Platelets as a Surrogate for Platelet Production}

In healthy individuals, platelets circulate for 7-10 days unless consumed as part of a hemostatic response. Newly synthesized (reticulated) platelets are released from bone marrow megakaryocytes and these platelets are larger in size and contain ribonucleic acid (RNA) [35] which can be used by platelets for protein synthesis [36, 37]. RNA levels can be estimated by mixing whole blood samples with thiazole orange (TO) and measuring fluorescence activity in a flow cytometer, although a standard TO labeling protocol needs to be rigorously followed and $\mathrm{TO}^{\text {bright }}$ and $\mathrm{TO}^{\text {dull }}$ gates clearly defined. Values for healthy ranges of $\mathrm{TO}$ staining can be challenging to set as platelet autofluorescence contributes significant background signal in this assay. Modern blood analyzers also use this approach to calculate the immature platelet fraction (IPF) and the automated IPF has been shown to measure thrombopoiesis in real time and track treatment effectiveness in ITP [38, 39], predict bleeding [40] and helps distinguish between hypo- and hyper-proliferative thrombocytopenias [41]. Importantly, concordance between flow cytometric and automated analyzer approaches was achieved in ITP samples [42]; however, more work is required in larger patient cohorts to fully understand the implications of this measurement in predicting the course of the disease and in assisting decisions on therapy. Reticulated platelets have also recently been shown to carry high levels of human leukocyte antigen (HLA) I with good reproducibility [43]. This observation requires further detailed analysis to characterize the HLA-positive population as HLA I levels on platelets may be regulated by multiple means $[44,45]$.

\section{Evaluating Receptor Levels on Circulating Platelets}

Engagement of the platelet surface by antibodies targeting platelet proteins can lead to platelet activation. This is most readily seen in heparin-induced thrombocytopenia (HIT) where autoantibodies against platelet factor 4/heparin form an immune complex that can engage the antigen on the platelet surface via Fab regions and simultaneously interact with FcyRIIa on the platelet via the Fc portion resulting in platelet activation [46]. The binding and activation of FcyRIIa require that the pathological antibody binds to its antigenic target in an appropriate orientation that permits Fc interaction with platelet Fc $\gamma$ RIIa. To what extent ITPrelated antiplatelet autoantibody pathology triggers metalloproteolysis and other platelet activation and degranulation events remain to be determined; however, the Fc portion of PaIgG is likely to mediate platelet clearance by engaging with Fc receptor on monocytes and macrophages [5].

Using flow cytometry, levels of platelet receptors on circulating platelets can be measured in thrombocytopenic samples. In particular, altered levels of GPIb $\alpha, \alpha I I b$ and $\beta 3$ integrin subunits, GPVI and $P$-selectin may signal the presence of an activating anti-platelet antibody. Whilst the mechanisms by which these receptors are regulated in vivo remain unclear, a number of platelet receptors can be metalloproteolytically shed from platelets, particularly upon engagement of the platelet antigen by an antiplatelet autoantibody. Being able to assess one or more shed ectodomain fragments in plasma using enzyme-linked immunosorbent assays (ELISA) offers flexibility in sample acquisition and storage for batch analysis. Notably, a small number of ITP patients who presented with bleeding were shown to have an antiGPVI autoantibody [9, 10], with evidence of platelet activation and metalloproteolysis of GPVI, resulting in the release of the GPVI ectodomain (sGPVI) and loss of collagen-related platelet function. Whether other platelet autoantibodies, particularly antibodies against GPIb $\alpha$ also trigger shedding of platelet receptors, and whether monitoring the loss of receptor ectodomains by flow cytometry of patient platelets in whole blood, or measurement of one or more shed ectodomain fragments in patient plasma has any value in assessing the presence of a platelet-activating antibody are open research questions. For example, a significant increase in soluble GPVI as quantified by ELISA signaled the presence of an acquired anti-GPVI autoantibody [47, 48]. These measurements explained the loss of collagen responsiveness in platelet aggregation assays as well as the observed bleeding that could not be explained by the platelet count $[9,10,49]$.

In contrast to GPVI, GPIb $\alpha$ is constitutively shed from platelets, and whilst the shed portion of GPIb $\alpha$ (glycocalicin) can be monitored by ELISA, the value of this measurement in reporting on anti-platelet autoantibody-induced platelet activation is not clear. Plasma levels of glycocalicin vary considerably in healthy donors and loss of GPIb $\alpha$ can be triggered by one or more nonantibody mediated mechanisms [38,50-52]. A more useful approach might be to evaluate the extent of intact receptors loss (for example GPIb $\alpha$ ) relative to the age of the platelet population as determined by TO uptake or other methods [38]. In this way, changes to the normal lifespan of circulating platelets, and increases in platelet production (proportion of TO+/GPIb $\alpha+$ platelets) can be monitored for assessment of acute phases of ITP and responses to therapy.

Autoantibodies that target GPIb $\alpha$ seem to increase platelet clearance by triggering receptor clustering, platelet degranulation to expose $P$-selectin and phosphatidylserine, and to release neuraminidases which remove (desialylate) sialic acid residues that cap $N$ - and $O$-linked carbohydrate moieties on the platelet surface [27,53-55]. Levels of platelet desialylation can be estimated by assessing the ability of glycan-binding lectins such as Ricinus Communis agglutinin-1 or wheat germ agglutinin to bind to exposed galactose or $\mathrm{N}$-acetylglucosamine residues, respectively, on washed platelets. Along with an improved understanding of ITP pathology, these findings may also have clinical implications as in a murine model of ITP [56], mice with anti-GPIb $\alpha$ autoantibodies were resistant to intravenous immunoglobulin (IVIg) a common therapy used to treat ITP in patients refractory to 
steroids. Further, in selected ITP patients with anti-GPIb $\alpha$ autoantibodies, recovery of the platelet count was observed after treatment with oseltamivir, a neuraminidase inhibitor suggesting that neuraminidase activity was a significant mediator of pathology in these individuals [29, 30]. Accurate identification of GPIb $\alpha$ autoantibodies, estimation of platelet desialylation or elevated platelet-associated or plasma neuraminidase activity in patients with ITP represent new approaches that may aid clinical decisions with regards to therapy. Such approaches require significant technical expertise, access to freshly drawn blood and sometimes washed platelets and a clear understanding of physiological and pathophysiological ranges for each parameter.

\section{Evaluating Platelet and Megakaryocyte Dysfunction}

Bleeding is observed in primary ITP, and often the extent of bleeding is out of step with the platelet count, implying that a platelet function defect has been acquired as part of the ITP etiology in many patients with bleeding issues [57]. However, all of the currently available approaches to evaluate platelet function in a clinical setting (light transmission and multiplate aggregometry, platelet function analyzer-100, thromboelastometry) are standardized for platelet counts greater than $100 \times 10^{9} / \mathrm{L}$ and require $>30 \times 10^{9}$ platelets $/ \mathrm{L}$ to achieve a blood clot as the measured endpoint. Thus, it can be difficult to ascertain the presence of a platelet functional defect and associated bleeding risk in ITP. However, in the research setting and in some clinical trials, viscoelastic testing (TEG, ROTEM, ClotPro), which provides a rapid assessment of clot formation and lysis in whole blood under low shear conditions, may provide meaningful data on thrombocytopenic samples [40,57-60]. Measurements including clot firmness and alpha angle have demonstrated utility in the context of ITP [57]. Furthermore, by subtracting clot amplitude parameters, such as A10, obtained from the fibrin-specific FibTEM parameters (wherein platelets are neutralized through the addition of cytochalasin-D), from the extrinsically activated EXTEM A10 value, an indication of platelet function can be obtained even in patients with a platelet count $<20$ $\mathrm{x} 10^{9} / \mathrm{L}$ [61]. Of course, to assess the utility of thromboelastometry to identify a platelet defect in ITP, ranges for these values in thrombocytopenic samples with no platelet function defect must first be established. ROTEM has, however, been used to predict the onset of thrombocytopenia and hypofibrinogenemia after cardiac bypass surgery $[62,63]$ suggesting such an approach is feasible.

Since the target antigens of antiplatelet autoantibodies are present on both platelets and the precursor megakaryocytes, autoantibodies may also disrupt megakaryopoiesis and thrombopoiesis in ITP. The ability of anti-platelet autoantibodies to impact megakaryocyte function is established as a platelet-independent mechanism of thrombocytopenia [64, 65]. Megakaryocyte numbers are generally normal or increased in ITP however these bone marrow cells show signs of apoptosis and enhanced immune cell proximity [66, 67]. The plasma of ITP patients has been shown to inhibit mature megakaryocyte function, resulting in decreased platelet production despite normal megakaryocyte numbers [68]. With the advent of high fidelity megakaryocyte cell lines [69], it may be possible to design a simple screening assay to evaluate the effect of ITP patient plasma on megakaryocyte rates of maturation and proplatelet production [70]. This would allow discrimination between the contributions to thrombocytopenia of inhibited platelet production and peripheral platelet destruction and may help predict responsiveness to thrombopoietin mimetics.

\section{Measuring and Identifying Changes in Immune Cell Subsets}

In many ITP patients, autoantibodies drive premature destruction of antibody-coated platelets. However, a variety of T cell irregularities have also been described in patients with ITP. These abnormalities, facilitated by splenic $\mathrm{T}$ follicular helper cells, result in the proliferation and differentiation of autoreactive $B$ cells which produce antiplatelet autoantibodies [13]. Reductions in both number and function of T-regulatory cells (Tregs), which suppress self-reactive lymphocytes and preserve immunological self-tolerance, have been recorded in ITP [71]. Along with the decreased function of anti-inflammatory IL-10-secreting B regulatory cells [72], a shift in the balance of T-helper cell (Th) types occurs, with decreased Th2 polarization resulting in an increased ratio of Th1 to Th2, which may enhance macrophage activation [73]. Numbers of CD8+ cytotoxic T cells are also elevated in peripheral blood and in the bone marrow of ITP patients [74]. Modern systems for polychromatic flow cytometry yield up to 20 distinct channels of data for a given cell and can rapidly process millions of cells per sample. Nonetheless, developing standardized methodology to accurately quantify and immunophenotype specific low-abundance subsets of immune cells involving highly multiplexed (minimally 16-color) flow cytometry panels remains extremely challenging [75]. The advent of mass cytometry $[76,77]$ and spectral flow cytometry [78] means that the resolution of antigen-specific $\mathrm{T}$ and $\mathrm{B}$ cell subsets is now possible; the application of these systems to the analysis of ITP patient blood remains a future possibility. More feasible is the standardization of assays to evaluate specific functional changes of ITP patient and control macrophage, monocyte, $\mathrm{B}$ and $\mathrm{T}$ cell subsets, such as cytokine production (e.g. IL-17) [13], phagocytic potential and detection of platelet-reactive T and B cells [79, 80].

\section{Concluding Remarks and Outlook}

ITP is a syndrome resulting from disturbances of one or more immune pathways that vary from patient to patient. Whilst the main triggering factor is often never determined, monitoring discrete changes in platelet biology and biochemistry as well as the innate and adaptive immune system will provide clues as to the pathogenesis and the course of the disease, and is also likely to identify subsets of patients who may be predisposed to respond to specific treatments. Evaluating the ascendancy of peripheral versus central mechanisms driving thrombocytopenia in patients will enable improved and tailored therapeutic strategies to treat autoantibody versus CD8 + T cell-mediated platelet destruction.

\section{Authorship}

S.M.H and E.E.G drafted the manuscript. All authors contributed to the review of the manuscript. Images were created with the help of https:// smart.servier.com/

\section{Funding}

This work was supported by the National Health and Medical Research Council of Australia, the Australian Research Council, the National Blood Authority and the Australian Capital Territory Department of Health. SMH was supported by an Australian Postgraduate Scholarship.

\section{Conflict of interest disclosure}

The authors declare no competing financial interests.

\section{ORCID}

Sarah M. Hicks (D) http://orcid.org/0000-0001-5712-124X

Lucy A. Coupland (D) http://orcid.org/0000-0002-8912-9534

Philip Y. Choi (D) http://orcid.org/0000-0001-9340-8125

Elizabeth E. Gardiner (D) http://orcid.org/0000-0001-9453-9688 


\section{References}

1. Rodeghiero F, Stasi R, Gernsheimer T, Michel M, Provan D, Arnold DM, Bussel JB, Cines DB, Chong BH, Cooper N, et al. Standardization of terminology, definitions and outcome criteria in immune thrombocytopenic purpura of adults and children: report from an international working group. Blood 2009;113:2386-2393.

2. Neunert CE. Management of newly diagnosed immune thrombocytopenia: can we change outcomes? Blood Adv 2017;1:2295-2301.

3. Arnold DM, Nazy I, Clare R, Jaffer AM, Aubie B, Li N, Kelton JG. Misdiagnosis of primary immune thrombocytopenia and frequency of bleeding: lessons from the McMaster ITP Registry. Blood Adv 2017;1:2414-2420.

4. Chong BH, Choi PY, Khachigian L, Perdomo J. Drug-induced immune thrombocytopenia. Hematol Oncol Clin North Am 2013;27:521-540.

5. Zufferey A, Kapur R, Semple JW. Pathogenesis and therapeutic mechanisms in immune thrombocytopenia (ITP). J Clin Med 2017;6:16.

6. McMillan R. Autoantibodies and autoantigens in chronic immune thrombocytopenic purpura. Semin Hematol 2000;37:239-248.

7. He R, Reid DM, Jones CE, Shulman NR. Spectrum of Ig classes, specificities, and titers of serum antiglycoproteins in chronic idiopathic thrombocytopenic purpura. Blood 1994;83:1024-1032.

8. Vollenberg R, Jouni R, Norris PAA, Burg-Roderfeld M, Cooper N, Rummel MJ, Bein G, Marini I, Bayat B, Burack R, et al. Glycoprotein V is a relevant immune target in patients with immune thrombocytopenia. Haematologica 2019;104:1237-1243.

9. Rabbolini DJ, Gardiner EE, Morel-Kopp M-C, Dunkley S, Jahangiri A, Lee CSM, Stevenson WS, Ward CM. Anti-glycoprotein VI mediated immune thrombocytopenia: an under-recognized and significant entity? Res Prac Thromb Haemost 2017;1:291-295.

10. Gardiner EE, Al-Tamimi M, Mu FT, Karunakaran D, Thom JY, Moroi M, Andrews RK, Berndt MC, Baker RI. Compromised ITAM-based platelet receptor function in a patient with immune thrombocytopenic purpura. J Thromb Haemost 2008;6:1175-1182.

11. Hiyoyama K, Wada H, Shimura M, Nakasaki T, Katayama N, Nishikawa M, Shiku H, Tahara T, Kato T. Increased serum levels of thrombopoietin in patients with thrombotic thrombocytopenic purpura, idiopathic thrombocytopenic purpura, or disseminated intravascular coagulation. Blood Coagul Fibrinolysis 1997;8:345-349.

12. Al-Samkari H, Kuter DJ. Thrombopoietin level predicts response to treatment with eltrombopag and romiplostim in immune thrombocytopenia. Am J Hematol 2018;93:1501-1508.

13. Audia S, Mahevas M, Samson M, Godeau B, Bonnotte B. Pathogenesis of immune thrombocytopenia. Autoimmun Rev 2017;16:620-632.

14. Olsson B, Andersson PO, Jernas M, Jacobsson S, Carlsson B, Carlsson LM, Wadenvik H. T-cell-mediated cytotoxicity toward platelets in chronic idiopathic thrombocytopenic purpura. Nat Med 2003;9:1123-1124.

15. Li S, Wang L, Zhao C, Li L, Peng J, Hou M. CD8+ T cells suppress autologous megakaryocyte apoptosis in idiopathic thrombocytopenic purpura. Br J Haematol 2007;139:605-611.

16. Lambert MP, Gernsheimer TB. Clinical updates in adult immune thrombocytopenia. Blood 2017;129:2829-2835.

17. Swain F, Bird R. How I approach new onset thrombocytopenia. Platelets 2019. in press.

18. Greinacher A, Pecci A, Kunishima S, Althaus K, Nurden P, Balduini CL, Bakchoul T. Diagnosis of inherited platelet disorders on a blood smear: a tool to facilitate worldwide diagnosis of platelet disorders. J Thromb Haemost 2017;15:1511-1521.

19. Noris P, Biino G, Pecci A, Civaschi E, Savoia A, Seri M, Melazzini F, Loffredo G, Russo G, Bozzi V, et al. Platelet diameters in inherited thrombocytopenias: analysis of 376 patients with all known disorders. Blood 2014;124:e4-e10.

20. Lamy T, Moisan A, Dauriac C, Ghandour C, Morice P, Le Prise PY. Splenectomy in idiopathic thrombocytopenic purpura: its correlation with the sequestration of autologous indium-111-labeled platelets. J Nucl Med 1993;34:182-186.

21. Roca M, Muniz-Diaz E, Mora J, Romero-Zayas I, Ramon O, Roig I, Pujol-Moix N. The scintigraphic index spleen/liver at 30 minutes predicts the success of splenectomy in persistent and chronic primary immune thrombocytopenia. Am J Hematol 2011;86:909-913.

22. Sarpatwari A, Provan D, Erqou S, Sobnack R, David Tai FW, Newland AC (2010) Autologous 111 In-labelled platelet sequestration studies in patients with primary immune thrombocytopenia (ITP) prior to splenectomy: a report from the United Kingdom ITP Registry. Br J Haematol 151, 477-487.
23. Siegel RS, Rae JL, Barth S, Coleman RE, Reba RC, Kurlander R, Rosse WF. Platelet survival and turnover: important factors in predicting response to splenectomy in immune thrombocytopenic purpura. Am J Hematol 1989;30:206-212.

24. McMillan R, Wang L, Tani P. Prospective evaluation of the immunobead assay for the diagnosis of adult chronic immune thrombocytopenic purpura (ITP). J Thromb Haemost 2003;1:485-491.

25. He R, Reid D, Jones C, Shulman N. Spectrum of Ig classes, specificities, and titers of serum antiglycoproteins in chronic idiopathic thrombocytopenic purpura. Blood 1994;83:1024-1032.

26. Zeng Q, Zhu L, Tao L, Bao J, Yang M, Simpson EK, Li C, van der Wal DE, Chen P, Spring CM, et al. Relative efficacy of steroid therapy in immune thrombocytopenia mediated by anti-platelet GPIIbIIIa versus GPIbalpha antibodies. Am J Hematol 2012;87:206-208.

27. Li J, van der Wal DE, Zhu G, Xu M, Yougbare I, Ma L, Vadasz B, Carrim N, Grozovsky R, Ruan M, et al. Desialylation is a mechanism of Fc-independent platelet clearance and a therapeutic target in immune thrombocytopenia. Nat Commun 2015;6:e7737.

28. Grimaldi D, Canoui-Poitrine F, Croisille L, Lee K, Roudot-Thoraval F, Languille L, Khellaf M, Michel M, Godeau B, Bierling P. Antiplatelet antibodies detected by the MAIPA assay in newly diagnosed immune thrombocytopenia are associated with chronic outcome and higher risk of bleeding. Ann Hematol 2014;93:309-315.

29. Shao L, Wu Y, Zhou H, Qin P, Ni H, Peng J, Hou M. Successful treatment with oseltamivir phosphate in a patient with chronic immune thrombocytopenia positive for anti-GPIb/IX autoantibody. Platelets 2015;26:495-497.

30. Revilla N, Corral J, Miñano A, Mingot-Castellano ME, Campos RM, Velasco F, Gonzalez N, Galvez E, Berrueco R, Fuentes I, et al. Multirefractory primary immune thrombocytopenia; targeting the decreased sialic acid content. Platelets 2019;30:743-751.

31. Marini I, Zlamal J, Faul C, Holzer U, Hammer S, Pelzl L, Bethge W, Althaus K, Bakchoul T. Autoantibody-mediated desialylation impairs human thrombopoiesis and platelet life span. Haematologica 2019.

32. Kiefel V. The MAIPA assay and its applications in immunohaematology. Transf Med 1992;2:181-188.

33. Provan D, Stasi R, Newland AC, Blanchette VS, Bolton-Maggs P, Bussel JB, Chong BH, Cines DB, Gernsheimer TB, Godeau B, et al. International consensus report on the investigation and management of primary immune thrombocytopenia. Blood 2010;115:168-186.

34. Brighton TA, Evans S, Castaldi PA, Chesterman CN, Chong BH. Prospective evaluation of the clinical usefulness of an antigen- specific assay (MAIPA) in idiopathic thrombocytopenic purpura and other immune thrombocytopenias. Blood 1996;88:194-201.

35. Robinson M, MacHin S, Mackie I, Harrison P. In vivo biotinylation studies: specificity of labelling of reticulated platelets by thiazole orange and mepacrine. Br J Haematol 2000;108:859-864.

36. Denis MM, Tolley ND, Bunting $M$, Schwertz $H$, Jiang $H$, Lindemann S, Yost CC, Rubner FJ, Albertine KH, Swoboda KJ, et al. Escaping the nuclear confines: signal-dependent pre-mRNA splicing in anucleate platelets. Cell 2005;122:379-391.

37. Nassa G, Giurato G, Cimmino G, Rizzo F, Ravo M, Salvati A, Nyman TA, Zhu Y, Vesterlund M, Lehtio J, et al. Splicing of platelet resident pre-mRNAs upon activation by physiological stimuli results in functionally relevant proteome modifications. Sci Rep 2018;8:498.

38. Barsam SJ, Psaila B, Forestier M, Page LK, Sloane PA, Geyer JT, Villarica GO, Ruisi MM, Gernsheimer TB, Beer JH, et al. Platelet production and platelet destruction: assessing mechanisms of treatment effect in immune thrombocytopenia (ITP). Blood 2011;117:5723-5732.

39. Ferreira FLB, Colella MP, Medina SS, Costa-Lima C, Fiusa MML, Costa LNG, Orsi FA, Annichino-Bizzacchi JM, Fertrin KY, Gilberti MFP, et al. Evaluation of the immature platelet fraction contribute to the differential diagnosis of hereditary, immune and other acquired thrombocytopenias. Sci Rep 2017;7:3355.

40. Estcourt LJ, Stanworth SJ, Harrison P, Powter G, McClure M, Murphy MF, Mumford AD. Prospective observational cohort study of the association between thromboelastometry, coagulation and platelet parameters and bleeding in patients with haematological malignanciesthe ATHENA study. Br J Haematol 2014;166:581-591.

41. Hoffmann JJ. Reticulated platelets: analytical aspects and clinical utility. Clin Chem Lab Med 2014;52:1107-1117.

42. Ibrahim H, Nadipalli S, Usmani S, DeLao T, Green L, Kleiman NS. Detection and quantification of circulating immature platelets: 
agreement between flow cytometric and automated detection. J Thromb Thrombolysis 2016;42:77-83.

43. Angenieux C, Dupuis A, Gachet C, de la Salle H, Maitre B. Cell surface expression of HLA I molecules as a marker of young platelets. J Thromb Haemost 2019;17:1511-1521.

44. Pavenski K, Freedman J, Semple JW. HLA alloimmunization against platelet transfusions: pathophysiology, significance, prevention and management. Tissue Antigens 2012;79:237-245.

45. Rowley JW, Oler AJ, Tolley ND, Hunter BN, Low EN, Nix DA, Yost CC, Zimmerman GA, Weyrich AS. Genome-wide RNA-seq analysis of human and mouse platelet transcriptomes. Blood 2011;118:e101-e111.

46. Greinacher A. Heparin-induced thrombocytopenia. J Thromb Haemost 2009;7(Suppl 1):9-12.

47. Nurden P, Tandon N, Takizawa H, Couzi L, Morel D, Fiore M, Pillois X, Loyau S, Jandrot-Perrus M, Nurden AT. An acquired inhibitor to the GPVI platelet collagen receptor in a patient with lupus nephritis. J Thromb Haemost 2009;7:1541-1549.

48. Gardiner EE, Thom JY, Al-Tamimi M, Hughes A, Berndt MC, Andrews RK, Baker RI. Restored platelet function after romiplostim treatment in a patient with immune thrombocytopenic purpura. Brit J Haematol 2010;149:625-628.

49. Moroi M, Jung SM, Okuma M, Shinmyozu K. A patient with platelets deficient in glycoprotein VI that lack both collagen-induced aggregation and adhesion. J Clin Invest 1989;84:1440-1445.

50. Coller BS, Kalomiris E, Steinberg M, Scudder LE. Evidence that glycocalicin circulates in normal plasma. J Clin Invest 1984;73:794-799.

51. Khaspekova SG, Shustova ON, Golubeva NV, Vasiliev SA, Mazurov AV. Relationships of mean platelet volume and plasma thrombopoietin with glycocalicin levels in thrombocytopenic patients. Acta Haematol 2015;133:295-299.

52. Forestier M, Al-Tamimi M, Gardiner EE, Hermann C, Meyer SC, Beer JH. Diesel exhaust particles impair platelet response to collagen and are associated with GPIb $\alpha$ shedding. Toxicol In Vitro 2012;26:930-938.

53. Urbanus RT, van der Wal DE, Koekman CA, Huisman A, van den Heuvel DJ, Gerritsen HC, Deckmyn H, Akkerman J-WN, Schutgens REG, Gitz E. Patient autoantibodies induce platelet destruction signals via raft-associated glycoprotein Ib $\alpha$ and Fc $\gamma$ RIIa in immune thrombocytopenia. Haematologica 2013;98:e70-e72.

54. van der Wal DE, Davis AM, Mach M, Marks DC. The role of neuraminidase 1 and 2 in glycoprotein Ib $\alpha$-mediated integrin $\alpha \operatorname{IIb} \beta 3$ activation. Haematologica 2019; e215830.

55. Grozovsky R, Giannini S, Falet H, Hoffmeister KM. Regulating billions of blood platelets: glycans and beyond. Blood 2015;126:1877-1884.

56. Webster ML, Sayeh E, Crow M, Chen P, Nieswandt B, Freedman J, $\mathrm{Ni} H$. Relative efficacy of intravenous immunoglobulin $\mathrm{G}$ in ameliorating thrombocytopenia induced by antiplatelet GPIIbIIIa versus GPIb $\alpha$ antibodies. Blood 2006;108:943-946.

57. Greene LA, Chen S, Seery C, Imahiyerobo AM, Bussel JB. Beyond the platelet count: immature platelet fraction and thromboelastometry correlate with bleeding in patients with immune thrombocytopenia. Br J Haematol 2014;166:592-600.

58. Gunduz E, Akay OM, Bal C, Gulbas Z. Can thrombelastography be a new tool to assess bleeding risk in patients with idiopathic thrombocytopenic purpura? Platelets 2011;22:516-520.

59. Alvarez-Roman MT, Fernandez-Bello I, Jimenez-Yuste V, MartinSalces M, Arias-Salgado EG, Rivas Pollmar MI, Justo Sanz R, Butta NV. Procoagulant profile in patients with immune thrombocytopenia. Br J Haematol 2016;175:925-934.

60. Opheim EN, Apelseth TO, Stanworth SJ, Eide GE, Hervig T. Thromboelastography may predict risk of grade 2 bleeding in thrombocytopenic patients. Vox Sang 2017;112:578-585.

61. Choi PY-I, Hicks S, Gardiner EE, Crispin P, Slade J, D'Rozario J, Parish C, Coupland L. Platelet dysfunction detected using rotational thromboelastometry (ROTEM) in severely thrombocytopenic patients with a bleeding phenotype. Blood 2019;134:2357.

62. Ji SM, Kim SH, Nam JS, Yun HJ, Choi JH, Lee EH, Choi IC. Predictive value of rotational thromboelastometry during cardiopulmonary bypass for thrombocytopenia and hypofibrinogenemia after weaning of cardiopulmonary bypass. Korean J Anesthesiol 2015;68:241-248.

63. Zwifelhofer NMJ, Bercovitz RS, Cole R, Yan K, Simpson PM, Moroi A, Newman PJ, Niebler RA, Scott JP, Stuth EAD, et al. Platelet function changes during neonatal cardiopulmonary bypass surgery: mechanistic basis and lack of correlation with excessive bleeding. Thromb Haemost 2020;120:94-106.

64. McMillan R, Wang L, Tomer A, Nichol J, Pistillo J. Suppression of in vitro megakaryocyte production by antiplatelet autoantibodies from adult patients with chronic ITP. Blood 2004;103:13 64-1369.

65. Chang M, Nakagawa PA, Williams SA, Schwartz MR, Imfeld KL, Buzby JS, Nugent DJ. Immune thrombocytopenic purpura (ITP) plasma and purified ITP monoclonal autoantibodies inhibit megakaryocytopoiesis in vitro. Blood 2003;102:887-895.

66. Houwerzijl EJ, Blom NR, van der Want JJ, Esselink MT, Koornstra JJ, Smit JW, Louwes H, Vellenga E, de Wolf JT. Ultrastructural study shows morphologic features of apoptosis and para-apoptosis in megakaryocytes from patients with idiopathic thrombocytopenic purpura. Blood 2004;103:500-506.

67. Olsson B, Ridell B, Carlsson L, Jacobsson S, Wadenvik H. Recruitment of T cells into bone marrow of ITP patients possibly due to elevated expression of VLA-4 and CX3CR1. Blood 2008;112:1078-1084.

68. Perdomo J, Yan F, Chong BH. A megakaryocyte with no platelets: anti-platelet antibodies, apoptosis, and platelet production. Platelets 2013;24:98-106.

69. Seo $\mathrm{H}$, Chen SJ, Hashimoto $\mathrm{K}$, Endo $\mathrm{H}$, Nishi $\mathrm{Y}$, Ohta A, Yamamoto T, Hotta A, Sawaguchi A, Hayashi H, et al. A $\beta 1$-tubulin-based megakaryocyte maturation reporter system identifies novel drugs that promote platelet production. Blood Adv 2018;2:2262-2272.

70. Iraqi M, Perdomo J, Yan F, Choi PY, Chong BH. Immune thrombocytopenia: antiplatelet autoantibodies inhibit proplatelet formation by megakaryocytes and impair platelet production in vitro. Haematologica 2015;100:623-632.

71. Sakakura M, Wada H, Tawara I, Nobori T, Sugiyama T, Sagawa N, Shiku H. Reduced Cd4+Cd25+ T cells in patients with idiopathic thrombocytopenic purpura. Thromb Res 2007;120:187-193.

72. Li X, Zhong H, Bao W, Boulad N, Evangelista J, Haider MA, Bussel J, Yazdanbakhsh K. Defective regulatory B-cell compartment in patients with immune thrombocytopenia. Blood 2012;120:3318-3325.

73. Audia S, Rossato M, Santegoets K, Spijkers S, Wichers C, Bekker C, Bloem A, Boon L, Flinsenberg T, Compeer E, et al. Splenic TFH expansion participates in B-cell differentiation and antiplatelet-antibody production during immune thrombocytopenia. Blood 2014;124:2858-2866.

74. Zhao C, Li X, Zhang F, Wang L, Peng J, Hou M. Increased cytotoxic T-lymphocyte-mediated cytotoxicity predominant in patients with idiopathic thrombocytopenic purpura without platelet autoantibodies. Haematologica 2008;93:1428-1430.

75. Chattopadhyay PK, Gierahn TM, Roederer M, Love JC. Single-cell technologies for monitoring immune systems. Nat Immunol 2014;15:128-135.

76. Blair TA, Frelinger AL 3rd. Platelet surface marker analysis by mass cytometry. Platelets 2019;1-8.

77. Bendall SC, Nolan GP, Roederer M, Chattopadhyay PK. A deep profiler's guide to cytometry. Trends Immunol 2012;33:323-332.

78. Sanders CK, Mourant JR. Advantages of full spectrum flow cytometry. J Biomed Opt 2013;18:037004.

79. Salgame P, Abrams JS, Clayberger C, Goldstein H, Convit J, Modlin RL, Bloom BR. Differing lymphokine profiles of functional subsets of human CD4 and CD8 T cell clones. Science 1991;254:279-282.

80. Toltl LJ, Nazi I, Jafari R, Arnold DM. Piecing together the humoral and cellular mechanisms of immune thrombocytopenia. Semin Thromb Hemost 2011;37:631-639. 